\title{
Seasonal and ontogenetic variability in stomach size of Eurasian perch (Perca fluviatilis L.)
}

\author{
Juhani Pirhonen $^{1}$ (D) $\cdot$ Liisa Muuri $^{1}$ - Saara M. Kalliokoski ${ }^{1} \cdot$ Marko M. Puranen $^{1}$ • \\ Timo J. Marjomäki ${ }^{1}$
}

Received: 29 December 2018 / Accepted: 11 June 2019 / Published online: 22 June 2019

(C) The Author(s) 2019

\begin{abstract}
Eurasian perch (Perca fluviatilis) were sampled in April, from May to June and at the end of August to test whether the current season (i.e. feeding conditions) affects the fishes' stomach size (i.e. volume and weight). A wide range of size data were analysed to reveal the relationship between fish size (length and weight) and stomach size. No significant differences in length-specific stomach volume or stomach weight were found in fish sampled at different times of the year. However, there were differences between seasons in the size of the stomach in relation to body weight, as length-specific body weight changes during the year because of the development of gametes and changes in nutritional status. Both stomach volume and weight grew obeying the power function up to about $20 \mathrm{~cm}$ in total length of perch. Yet, the growth was faster than that predicted by the cube law in relation to fish length, i.e. allometric. In larger fish, stomach growth decreased in relation to growth in length, and the relative weight of the stomach even decreased in the largest size class. These dynamics match well with the typical pattern of growth and ontogenic shift in diet from small invertebrates to fish. A nonproportional power function relationship was found between stomach weight and stomach volume.
\end{abstract}

Keywords Percidae · Stomach capacity Stomach weight $\cdot$ Stomach volume $\cdot$ Ventriculus

\section{Introduction}

Fishes in temperate zone waters face large annual variation in ambient temperature. As poikilothermic animals, temperature directly influences fishes' metabolism and energy intake requirements. During the winter months, these are at their lowest, and they increase with the increase in temperature during spring and summer. The optimal temperature for growth of the

Juhani Pirhonen

juhani.pirhonen@jyu.fi

1 Department of Biological and Environmental Science, University of Jyvaskyla, P.O. Box 35,

FIN-40014 Jyvaskyla, Finland 
Eurasian perch (Perca fluviatilis), which is a valuable species for commercial and recreational fisheries throughout Europe, is $>25{ }^{\circ} \mathrm{C}$ (Mélard et al. 1996). A study by Popova and Sytina (1977) showed that perch fed minimally during winter months and their ration size rapidly increased during May. However, perch is known to actively eat during winter, and in, for example, Finland, it is the most important target species for ice-fishing competitions.

Stomach (ventriculus) size (i.e. volume and weight) increases with an animal's size. The stomach is a flexible part of the digestive system, and its size typically adjusts to the expected maximum ration size (Ruohonen and Grove 1996). There is a very limited amount of information available on changes in stomach capacity, and it would be useful to better understand how fishes react to changes in food quality and availability and how ontogenetic changes may affect stomach capacity. Experimental evidence shows that stomach size is affected by the water content of food (Ruohonen and Grove 1996) and by feeding frequency (Känkänen and Pirhonen 2009). For example, rainbow trout (Oncorhynchus mykiss) fed energy-rich pelleted dry feed had significantly smaller stomachs than when fed with Baltic herring (Clupea harengus membras; Ruohonen and Grove 1996). Also, when both whitefish (Coregonus lavaretus) and pikeperch (Sander lucioperca) were fed as much as they desired less frequently than once per day, their stomachs became larger in order to ingest larger ration sizes than if they had been fed daily (Känkänen and Pirhonen 2009; Mattila et al. 2009).

The processes that expand the stomach (i.e. stomach capacity upregulation) are relatively well known, but information about possible downregulation during periods of decreased food intake or starvation appears to be absent. It has been suggested that it is uneconomical to maintain extra stomach capacity (Ruohonen and Grove 1996), and consequently, fishes' stomach capacity can be expected to change based on the season and food size spectrum. Therefore, downregulation of stomach capacity can be expected to occur in fishes during periods of low or no feeding.

The increase of stomach volume with body weight has been found to be linear (i.e. directly proportional) in some cases (Jobling et al. 1977; Pirhonen and Koskela 2005; Känkänen and Pirhonen 2009). Others have found that it obeys the cube law (i.e. isometric growth, the exponent of the power function between length and a volume or weight variable $=3$, e.g. Froese 2006) in relation to length (Phelps et al. 2007), but not always (Mattila et al. 2009; Ruohonen and Grove 1996). In most studies dealing with stomach size, the range of fish sizes has been relatively narrow; only Ruohonen and Grove (1996) investigated fish with a wide range of sizes. As such, there is very limited information available on possible ontogenetic changes in stomach capacity.

This study focused on the stomach size of wild-caught perch, addressing the question of whether stomach size changes based on the season and fish size (i.e. length and weight). We hypothesised that the stomach size (i.e. weight and volume) of perch would be smallest in late winter and would increase in the spring, when fishes' energy requirements and feeding rapidly increase with temperature. We also hypothesised that the increase in stomach size would not be isometric in relation to size when perch of a wide range of sizes were examined.

\section{Materials and methods}

\section{Fish sampling}

Seasonal data include stomach size measurements collected after catching perch from

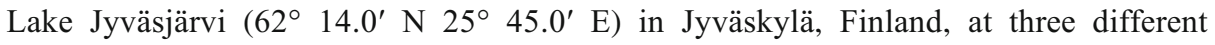


occasions in 2009 (Table 1). The first sample (52 individuals) was collected at the end of an ice-angling competition (7 April), when water temperature varied between 1.1 and $1.6{ }^{\circ} \mathrm{C}$. The second sample (50 individuals) was collected from 25 May to 2 June with angling and gill nets, with mesh sizes of 17 and $21 \mathrm{~mm}$, and a special gill net for research, which consisted of nine different mesh sizes: 10, 12, 15, 20, 25, 30, 35, 45 and $55 \mathrm{~mm}$. The sample was collected from the western end of the lake, close to the shoreline (water depth 2-6 m). The water temperature during that period was about $15{ }^{\circ} \mathrm{C}$. The third sample (51 individuals) was collected from 24 to 28 August. Only gill nets were used, and the water temperature was about $17{ }^{\circ} \mathrm{C}$. When gill nets were used, the nets were kept in the lake for only $3-4 \mathrm{~h}$ at a time to avoid excessive digestion of food (see Craig 1978). After sampling, all fish were sacrificed, chilled with crushed ice (except in April) and frozen at $-20{ }^{\circ} \mathrm{C}$ before analyses.

In addition, for analysis of the relationship between fish size and stomach size, perch were caught from Lake Ylisjärvi ( $61^{\circ} 54.1^{\prime} \mathrm{N} 25^{\circ} 44.4^{\prime} \mathrm{E}$ ), mainly during the winter (from 4 December to 2 April; $n=78$ ), with ice-fishing and gill nets, similar to method of obtaining the samples from Lake Jyväsjärvi. However, sampling was continued during the open water season (27 May and 9 September; $n=18$ ) to complement the data regarding larger individuals. This lake was selected because the possibility of catching fish with a wide range of sizes, including large perch, is rather good. In total, 96 perch were caught, 18 of which were over $30 \mathrm{~cm}$ in total length.

Angling was applied to expand the range and achieve greater distribution of length in the samples, as gill nets can be size-selective.

\section{Measurements}

To perform the measurements, the fish were defrosted, weighed with gonads to determine their total body weight ( $W$, accuracy $0.1 \mathrm{~g}$ ) and then without gonads to determine their somatic weight $(\operatorname{Som} W$, acc. $0.1 \mathrm{~g})$. Then, their total length was measured $(L$, acc. $1 \mathrm{~mm})$. The body cavity was opened, the gastrointestinal tract and gills were removed and sex was determined. All individuals were sexually mature. The stomach contents of each individual were emptied onto a Petri dish and weighed (acc. $0.01 \mathrm{~g}$ ). It was assumed in the measurements and calculations that the sampled fish had not vomited when captured.

Table 1 Mean, SD and range of total length, total body weight and stomach variables (volume, weight, volume/ weight and content) of perch (Perca fluviatilis) caught at three different times in 2009 in Lake Jyväsjärvi, Finland

\begin{tabular}{|c|c|c|c|c|c|c|c|c|c|}
\hline & \multicolumn{3}{|c|}{7 April $(n=52)$} & \multicolumn{3}{|c|}{25 May-2 June $(n=50)$} & \multicolumn{3}{|c|}{$24-28$ August $(n=51)$} \\
\hline & Mean & $\mathrm{SD}$ & Min-Max & Mean & $\mathrm{SD}$ & Min-Max & Mean & SD & Min-Max \\
\hline Total length $(\mathrm{cm})$ & 14.7 & 2.0 & $12.7-20.9$ & 14.5 & 2.5 & $11.8-23.0$ & 14.2 & 2.5 & $11.9-24.6$ \\
\hline Weight $(\mathrm{g})$ & 35.4 & 20.1 & $20.2-111.7$ & 32.4 & 26.8 & $14.0-153.0$ & 30.4 & 16.6 & $17.3-103.1$ \\
\hline \multicolumn{10}{|l|}{ Stomach } \\
\hline Volume (ml) & 1.63 & 2.17 & $0.35-9.60$ & 2.16 & 4.94 & $0.20-30.5$ & 1.17 & 2.23 & $0.20-15.6$ \\
\hline Volume $\%$ & 3.77 & 2.38 & $1.33-14.1$ & 4.22 & 3.66 & $1.31-19.9$ & 3.07 & 2.36 & $0.86-15.5$ \\
\hline Weight (g) & 0.25 & 0.22 & $0.09-1.12$ & 0.30 & 0.38 & $0.08-2.10$ & 0.22 & 0.21 & $0.06-1.25$ \\
\hline Weight $\%$ & 0.66 & 0.22 & $0.39-1.66$ & 0.79 & 0.26 & $0.42-1.48$ & 0.64 & 0.22 & $0.30-1.21$ \\
\hline Vol./weight $(\mathrm{ml} / \mathrm{g})$ & 5.53 & 2.07 & $2.65-13.52$ & 4.96 & 2.81 & $2.04-14.52$ & 4.54 & 2.12 & $1.79-14.21$ \\
\hline Content $(\mathrm{g})$ & 0.12 & 0.34 & $0.0-2.46$ & 0.45 & 1.21 & $0.0-6.96$ & 0.34 & 1.35 & $0.0-9.73$ \\
\hline
\end{tabular}


To measure stomach volume ( $S V, \mathrm{ml})$, a string was tied around the pyloric sphincter and the oesophagus was tied to a burette right underneath the gills. Stomach volume was estimated as the volume of water required to dilate the stomach with a pressure head of $50-\mathrm{cm}$ water (Jobling et al. 1977) at an accuracy of $0.1 \mathrm{ml}$. After volume measurement, the stomach was blotted dry and weighed (acc. $0.01 \mathrm{~g}$ ) to estimate stomach weight $(\mathrm{SW}, \mathrm{g})$.

Relative stomach volume and stomach weight were calculated as $R(\%)=100 X \times W^{-1}$, where $X$ is stomach volume $(\mathrm{ml})$ or stomach weight $(\mathrm{g})$ and $W$ is body weight $(\mathrm{g})$.

\section{Statistical analyses}

The effect of different seasons (April, May-June, August; Jyväsjärvi data) was assessed with the General Linear Model (GLM), in which season was a fixed factor and $\ln (L)$ was a covariate. The dependent variables - body weight, somatic weight (weight without the gonads), stomach volume, stomach weight and food weight - were also logarithmised $(\ln )$ for the analysis. Note that $\ln (x+0.001)$ represented food weight because there were zero observations. A power function $\left(y=a \times x^{b}\right)$ relationship between the non-logarithmised dependent variable and length was assumed for these data. The validity of the assumptions was assessed by performing routine diagnostics with the GLM. For simplicity of interpretation, no interaction was assumed between the season and covariate, meaning that the exponent in the power function was assumed to be constant. Further, for simplicity, sex was not considered as a factor in the GLM. Differences in stomach fullness (\%) between different sampling periods were tested with a non-parametric Kruskal-Wallis test.

The significance of the difference between slopes $\left(b_{x}, b_{y}\right)$ of regression for different variables $(X, Y)$ regarding total length in the Jyväsjärvi sample was assessed with the GLM. Perch individual-specific ( $i$ ) differences of the logarithmised variables, $\ln Y_{i}-\ln X_{i}$, are the dependent variables, $\ln \left(L_{\mathrm{i}}\right)$ is the covariate and season is the fixed factor. To test for the difference in slopes $\left(b_{x}, b_{y}\right)$, the $\mathrm{H}_{0}$ hypothesis was that parameter $\mathrm{B}$ in the GLM would be 0 if there was no difference between slopes. The significance of deviation from $\mathrm{H}_{0}$ was based on a routine $t$-test conducted with the GLM.

For a more comprehensive analysis of the effect of size (total length), broad data from Lake Ylisjärvi were used (total length $[\mathrm{cm}]$ : range $=7.2-41.1$, mean $=20.6$ and S.D. $=8.5$; weight [g]: range $=3.1-1137$, mean $=171$ and S.D. $=217$ ). Only individuals with $L \geq 12.0 \mathrm{~cm}$ were analysed because the observed stomach volume of smaller individuals was below the lower limit of measurement capacity. In this analysis, no prior assumptions were made regarding the mathematical relationship between stomach size and fish length. Instead, the relationship between the logarithmised dependent variable and total length was estimated using locally estimated scatterplot smoothing (LOESS). This was illustrated only for fish longer than $12 \mathrm{~cm}$ (total length) because our methodology could not sufficiently accurately estimate the stomach volume of smaller individuals.

\section{Results}

\section{Seasonal effects}

In Lake Jyväsjärvi perch data, the relationship between total length and total body weight (both variables $\ln$-transformed) differed significantly between seasons (GLM, $F=23.9$, df =2, 149, 
$p<0.001)$. The length-specific body weight was about $11 \%$ higher in both April and August compared with the spawning season in May-June after releasing the gametes (Table 2; GLM, $p<0.05$; $t$-test for seasonal intercepts: $t<-6.0, p<0.001$ for comparison between May-June and either April or August; no significant difference between April and August: $p=0.73$ ). On the other hand, the length-specific somatic weight was about $14 \%$ higher $(p<0.05)$ in August, at the latter part of the growing season, than in April, at the end of winter (GLM, $F=64.1, \mathrm{df}=$ $1,100, p<0.001$; Table 2).

Yet, the relationship between total length and stomach volume (Fig. 1a) or stomach weight (Fig. 1b) did not differ significantly between seasons (Table 2; GLM for $S V, F=2.76$, df =2, $147, p>0.066$; for $S W, F=1.14, \mathrm{df}=2,147, p=0.322$ ). Thus, while the length-specific total weight changed with the seasons, the stomach weight and stomach volume did not change significantly. The relationship of stomach volume and stomach weight to total body weight and somatic weight obviously differed between seasons due to the seasonal dynamics of both total and somatic weight.

The length-specific stomach content weight was significantly $(p<0.05)$ lower in April than in May-June or August (Table 2; GLM, $F=2,149, p<0.001$; comparison between April and either May-June or August $t$ test for seasonal effect: $t<-8.0, p<0.001$; no significant differences between May-June and August: $p=0.91$ ).

Table 2 Parameter estimates and their 95\% confidence intervals (CI) for the GLM of seasonal ln-transformed data of perch (Perca fluviatilis) from Lake Jyväsjärvi. Period (months) differing significantly $(p<0.05)$ from the others are marked with an asterisk. Adj. $r^{2}=$ coefficient of determination adjusted for the number of estimated parameters

\begin{tabular}{|c|c|c|c|c|c|c|c|c|c|}
\hline \multirow[t]{2}{*}{ Period } & \multirow[t]{2}{*}{ Dependent } & \multirow[t]{2}{*}{ Independent } & \multirow[t]{2}{*}{$a$} & \multicolumn{2}{|l|}{ CI } & \multirow[t]{2}{*}{$b$} & \multicolumn{2}{|l|}{$\mathrm{CI}$} & \multirow[t]{2}{*}{ Adj. $r^{2}$} \\
\hline & & & & Lower & Upper & & Lower & Upper & \\
\hline All & \multirow[t]{4}{*}{ Body weight } & \multirow[t]{4}{*}{ Total length } & & & & \multirow[t]{4}{*}{3.25} & \multirow[t]{4}{*}{3.15} & \multirow[t]{4}{*}{3.35} & \multirow[t]{4}{*}{0.97} \\
\hline IV & & & -5.24 & -5.46 & -5.01 & & & & \\
\hline $\mathrm{V}-\mathrm{VI}$ & & & $-5.14 *$ & -5.36 & -4.91 & & & & \\
\hline VIII & & & -5.24 & -5.50 & -4.98 & & & & \\
\hline All & \multirow[t]{3}{*}{ Somatic weight } & \multirow[t]{3}{*}{ Total length } & & & & \multirow[t]{3}{*}{3.17} & \multirow[t]{3}{*}{3.06} & \multirow[t]{3}{*}{3.28} & \multirow[t]{3}{*}{0.97} \\
\hline IV & & & $-5.18 *$ & -5.51 & -4.85 & & & & \\
\hline VIII & & & -5.06 & -5.36 & -4.76 & & & & \\
\hline All & Stomach volume & Total length & -15.0 & -16.5 & -13.6 & 5.60 & 5.07 & 6.13 & 0.74 \\
\hline All & Stomach volume & Body weight & -5.81 & -6.35 & -5.26 & 1.69 & 1.53 & 1.85 & 0.74 \\
\hline All & \multirow{3}{*}{ Stomach volume } & \multirow{3}{*}{ Somatic weight } & & & & \multirow[t]{3}{*}{1.62} & \multirow[t]{3}{*}{1.44} & \multirow[t]{3}{*}{1.81} & \multirow[t]{3}{*}{0.75} \\
\hline \multirow[t]{2}{*}{ IV } & & & $-5.34 *$ & -6.14 & -4.54 & & & & \\
\hline & & & -5.70 & -6.33 & -5.06 & & & & \\
\hline All & Stomach weight & Total length & -13.6 & -14.4 & -12.9 & 4.50 & 4.21 & 4.79 & 0.86 \\
\hline All & \multirow{4}{*}{ Stomach weight } & \multirow{4}{*}{ Body weight } & & & & \multirow{4}{*}{1.36} & \multirow{4}{*}{1.27} & 1.45 & 0.86 \\
\hline IV & & & -6.33 & -6.74 & -5.91 & & & & \\
\hline V-VI & & & $-6.09 *$ & -6.51 & -5.68 & & & & \\
\hline VIII & & & -6.30 & -6.61 & -6.00 & & & & \\
\hline All & Stomach volume & Somatic weight & & & & 1.36 & 1.25 & 1.48 & 0.85 \\
\hline IV & & & $-6.12 *$ & -6.61 & -5.63 & & & & \\
\hline VIII & & & -6.27 & -6.65 & -5.88 & & & & \\
\hline All & Food weight & Total length & & & & 5.27 & 3.77 & 6.77 & 0.35 \\
\hline IV & & & $-17.6^{*}$ & -22.1 & -13.1 & & & & \\
\hline $\mathrm{V}-\mathrm{VI}$ & & & -16.0 & -20.5 & -11.5 & & & & \\
\hline VIII & & & -16.1 & -20.0 & -12.1 & & & & \\
\hline
\end{tabular}




\section{Effects of fish size on stomach size}

For the size range of the sample from Lake Jyväsjärvi $(12.7-20.9 \mathrm{~cm})$, both stomach volume and stomach weight obeyed well the power function (linear for ln-transformed variables). Both variables grew in relation to total fish length significantly faster than total and somatic body weight ( $b$-values, Table 2; GLM with $\ln L$ as a covariate; $t=8.74, \mathrm{df}=1,149, p<0.001$ for difference in $\ln S V$ and $\ln W ; t=8.67 \mathrm{df}=1,149, p<0.001$ for $\ln S W$ and $\ln W ; t=16.36, \mathrm{df}=1$, $149, p<0.001$ for $\ln S V$ and Som $W ; t=8.45, \mathrm{df}=1,149, p<0.001$ for $\ln S W$ and Som $W$ ). Correspondingly, the $b$-values for body weight-stomach size regressions (Table 2) were significantly $(z$-test, $p<0.05)$ higher than 1 , indicating that stomach size variables did not grow in direct proportion to body weight $(b=1)$, but faster.

In addition, stomach volume increased significantly faster than stomach weight in relation to fish length (GLM with $\ln (L)$ as a covariate: $t=4.93, \mathrm{df}=1,149, p<0.001)$ and body weight $(t=5.21, \mathrm{df}=1,149, p<0.001 ; b$-values in Table 2$)$.

The amount of food in the stomach did not change at a significantly different rate than the stomach volume in relation to fish length (GLM with $\ln L$ as a covariate; $t=0.672, \mathrm{df}=1,149$, $p=0.672$ ).

Although the power function encapsulated the relationship between stomach size and fish length for the range of lengths of perch obtained from Lake Jyväsjärvi, it does not apply to larger length ranges. Examination of a wide range of total lengths from the Lake Ylisjärvi data $(12.2-41.1 \mathrm{~cm})$ revealed that, in small fish, stomach volume and weight grow quickly in relation to fish length (Fig. 2), but stomach growth gradually decreases with an increase in fish length. From lengths of about $25 \mathrm{~cm}$ onwards, the ratio of stomach volume to body weight becomes more or less constant (Fig. 2c). Further, relative stomach weight begins to decrease in the largest size class (Fig. 2d).

Overall, the length-specific stomach volume (compare Figs. 1a and 2a) and stomach weight (compare Figs. $1 \mathrm{~b}$ and $2 \mathrm{~b}$ ) match well for the range of lengths found in both Lakes Jyväsjärvi and Ylisjärvi.

As in the Lake Jyväsjärvi, also in Lake Ylisjärvi stomach volume grew faster than stomach weight in relation to fish length (GLM with $\ln L$ as a covariate; $t=3.45, p=0.001$ ).
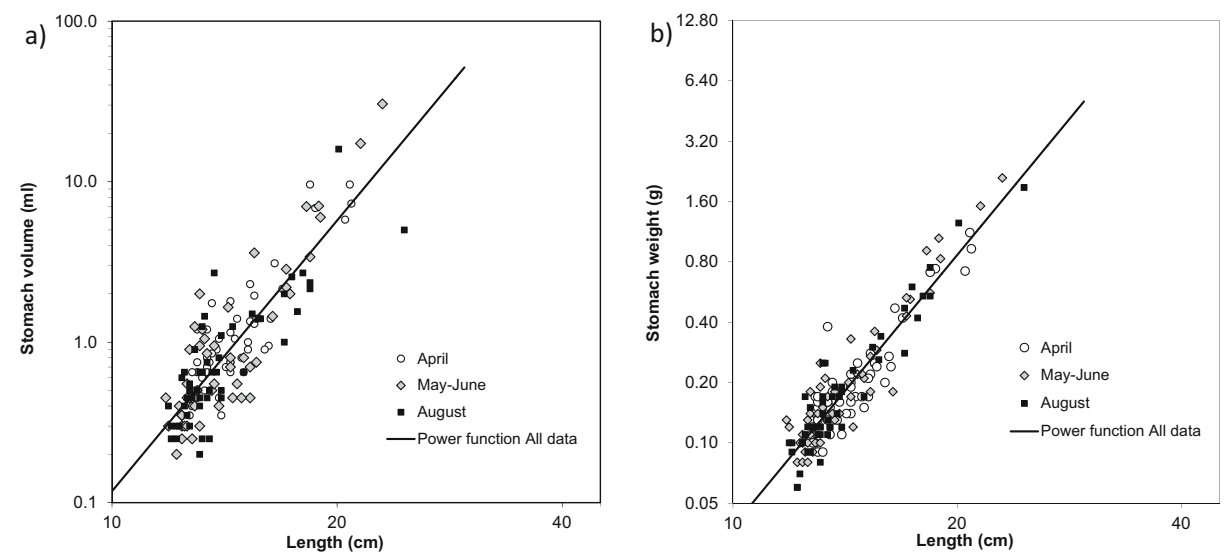

Fig. 1 The relationship between total length and a stomach volume and $\mathbf{b}$ stomach weight of perch caught in different seasons from Lake Jyväsjärvi. A power function was fitted to the data (for parameter estimates, see Table 2). Note: logarithmic scales on both axes 
Correspondently, a power function model (linear between the ln-transformed variables) fits well with the stomach volume and stomach weight observations from Lake Ylisjärvi (Fig. 3). The estimated exponent is 1.18 (s.e. $=0.046,95 \%$ confidence interval; $1.09-1.27$ ), which deviates significantly $(p<0.001)$ from $1\left(b=1\right.$ for $\mathrm{H}_{0}$ hypothesis regarding a proportional increase).

\section{Discussion}

To the authors' knowledge, this is the first study to investigate possible seasonal changes in stomach size in wild teleost fishes. The results indicate that there are no seasonal differences in the stomach size of perch if their length is standardised, contradicting our original hypothesis that stomach volume would considerably vary between seasons due to differences in feeding regime (as in experimental manipulations of a feeding regime, e.g. Ruohonen and Grove 1996). Yet, the quantity of food in the stomach was considerably lower during the winter (April) than during the summer, indicating low food intake during the winter. The difference in
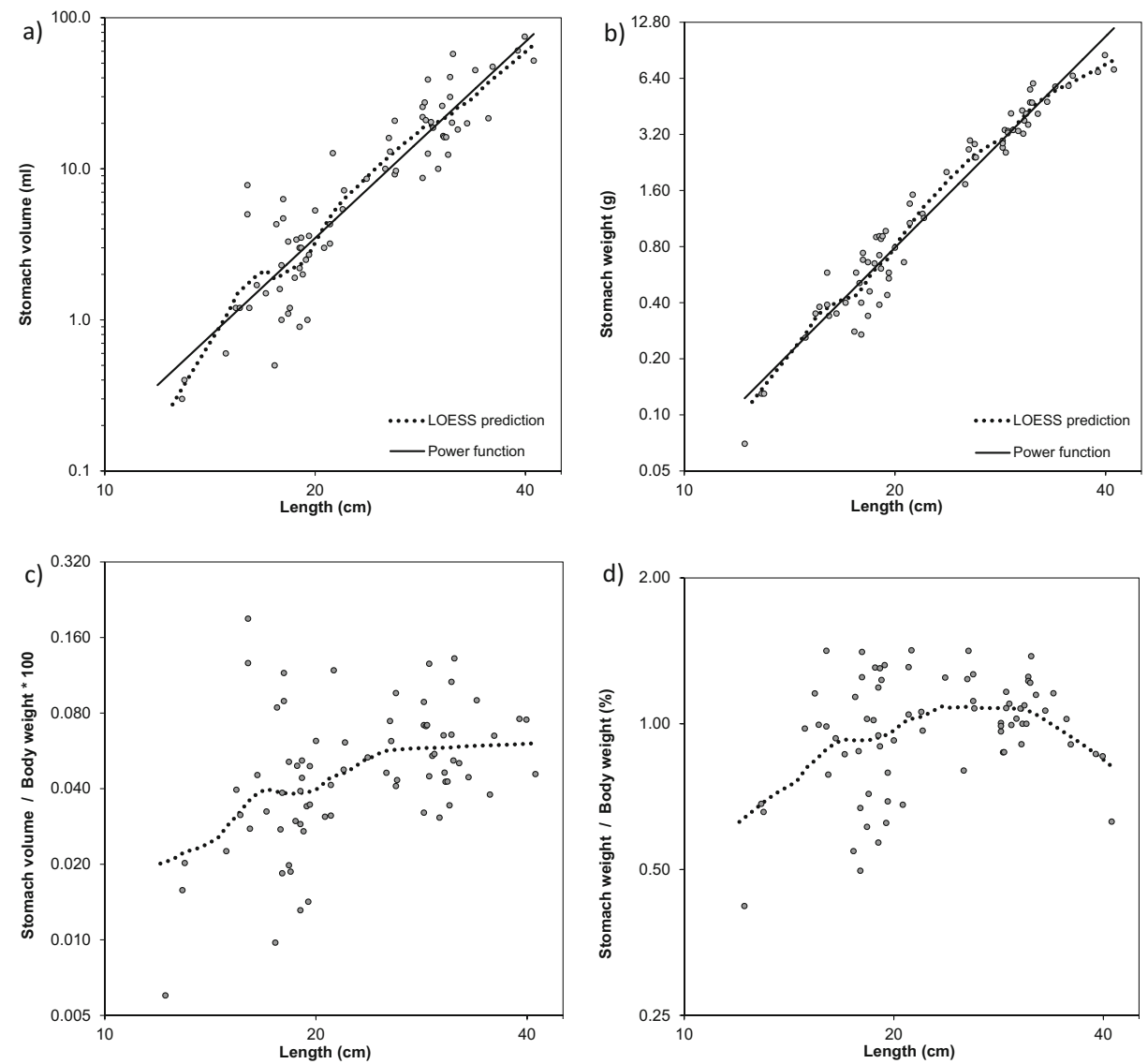

Fig. 2 The relationship between total length and a stomach volume, $\mathbf{b}$ stomach weight, $\mathbf{c}$ the ratio of stomach volume to body weight and $\mathbf{d}$ the ratio of stomach weight to body weight in perch caught from Lake Ylisjärvi. A power function and LOESS smoothing were fitted to the data. Note: logarithmic scales on both axes 


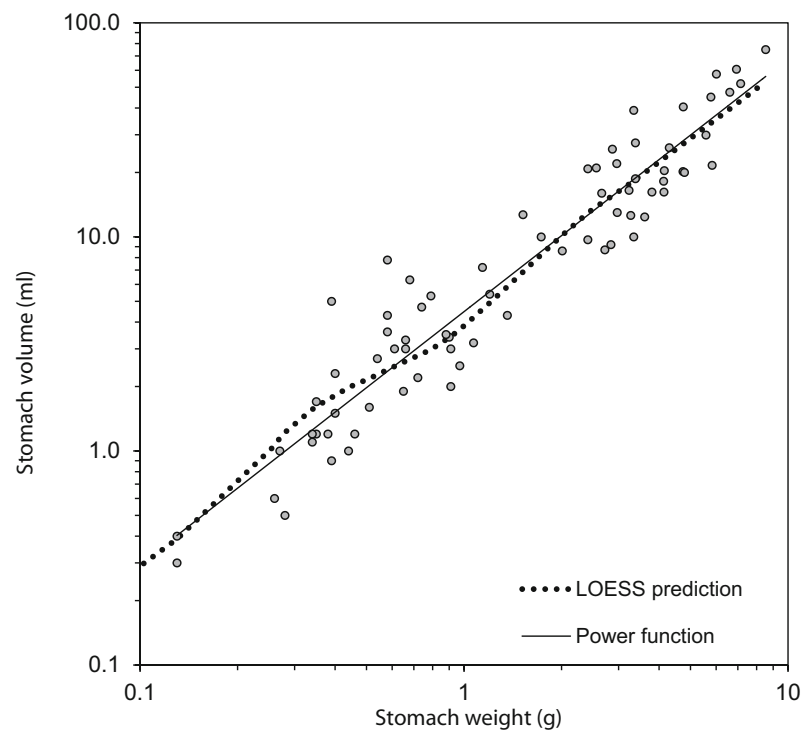

Fig. 3 The relationship between the stomach weight and stomach volume of perch caught from Lake Ylisjärvi. A power function and LOESS smoothing were fitted to the data. Note: logarithmic scale on both axes

feeding between the summer and winter is presumably even more prominent than estimated based on the amount of food in the fishes' stomachs because the rate at which food is evacuated from the stomach is much lower at very low temperatures in the winter than in the summer (Elliot and Persson 1978). On the other hand, the largest food items in the winter may be comparable or even larger in size compared with those in the summer; Craig (1978) and Schleuter and Eckmann (2008) found that perch had different diets in different seasons. Assuming food patchiness (Mehner and Wieser 1994) and slow evacuation (Elliot and Persson 1978), the stomach size requirements for successful feeding in winter may not differ much from those in the summer.

A considerable proportion of the energy consumption of the gastrointestinal tract in terrestrial animals is associated with the energy consumption of the intestine (Cant et al. 1996). This may also be the case in fishes. For example, Krogdahl and Bakke-McKellep (2005) reported that in Atlantic salmon (Salmo salar) weighing $>1 \mathrm{~kg}$, the average relative stomach weight decreased from 4.7 to $4.2 \mathrm{~g} \mathrm{~kg}^{-1}$ (i.e. c. 11\%) during a 40-day starvation period, while the relative weight of the pyloric caeca or other parts of the intestine decreased by $27-45 \%$. This suggests that even under severe starvation conditions, there is not always a major change in fishes' stomach volume. Similarly, German et al. (2010) reported a 70-78\% decrease in the surface area of the intestine of a detritivorous catfish (Pterygoplichthys disjunctivus) after a 150-day starvation period or low-energy feeding. However, information regarding stomach size was unavailable. Taken together, these findings suggest that the majority of possible downregulation of the digestive system takes place in the gut, rather than the stomach, during extended periods of low food intake.

Based on the present results, the average stomach size of perch in relation to total length remains constant throughout the year. Seasonal fluctuation in body weight must be taken into consideration when estimating the relationship between stomach size and body weight. Therefore, length is a more practical independent variable than body weight when stomach size is modelled in relation to fish size. 
Interestingly, there was considerable inter-individual variation in stomach weight and, in particular, stomach volume (Fig. 1) within perch of a similar length. If stomach size bears information about the prior feeding regime, as found in several laboratory experiments (Ruohonen and Grove 1996; Känkänen and Pirhonen 2009; Mattila et al. 2009), this implies significant individual specialisation in feeding. In other words, one perch may specialise in consuming small items (e.g. zooplankton), whereas another perch of the same size, perhaps in a different habitat, may specialise in larger items (e.g. invertebrates or fish) to reduce competition for food. Schleuter and Eckmann (2008) supported this, finding considerable individual specialisation in their stomach content study of perch. Inter-individual variability in taste preferences among common carp (Cyprinus carpio) was described by Kasumyan (2000), which can explain specialisation. Even large perch can change their dietary preferences between different seasons (Jacobsen et al. 2015).

The dependence of stomach size on fish size has been studied for several fish species, mostly those in captivity. However, there appears to be wide inter-specific variation regarding the fish size-stomach volume relationship. Jobling et al. (1977) reported a linear relationship between body weight and stomach volume, with an $r^{2}$-value of 0.95 in 50-200 g dab (Limanda limanda). The relationship was also linear for plaice (Pleuronectes platessa), with an $r^{2}$-value of 0.91 (Jobling 1980). On the other hand, in rainbow trout and whitefish, there is much greater variation in the body weight-stomach volume relationship, with typical $r^{2}$ values between 0.2 and 0.5 (Pirhonen and Koskela 2005; Känkänen and Pirhonen 2009). Also, the relationship is not necessarily linear (Ruohonen and Grove 1996).

Based on comparison of the present results with those obtained for another percid, pikeperch (Sander lucioperca), fed fish flesh in laboratory conditions at different frequencies (Mattila et al. 2009), two conclusions can be drawn: First, in both percids, the relationship of fish or stomach weight to stomach volume was non-linear. Second, the relationships observed in pikeperch fed only once a week very closely resembled the relationship observed in perch in the present experiment, while more frequently fed pikeperch had much smaller stomachs in relation to fish size. As such, the results of the present experiment suggest that perch are opportunistic feeders with elastic stomachs.

The relationship between fish length and stomach volume has been studied in closely related yellow perch (Perca flavescens; Phelps et al. 2007), with an observed size range very similar to that observed in Lake Jyväsjärvi perch in the present study. Phelps et al. (2007) found that the exponent of the power function was close to 3, implying isometric growth of stomach volume according to the cube law (e.g. Froese 2006). This contradicts our findings, as the exponent we obtained for Eurasian perch was greater than 5 .

The differences in the fish size-stomach size relationship between studies and species may be partly explained by the different size ranges of fish in these studies. Our results, which are based on a very wide size range of perch, strongly suggest that the relationship can be more complex than what is found for the narrow ranges examined in previous studies and for the range obtained from Lake Jyväsjärvi in this study. In perch, it appears that stomach size changes dynamically in relation to fish size during ontogeny in a growing fish. When fish are small, their stomachs grow quickly, and their relative size increases with length. In larger fish, stomach growth decreases, and the proportional weight of the stomach may decrease with growth. Thus, our data support our hypothesis that stomach and fish size grow non-isometrically.

Further, we found that the growth of stomach volume is non-isometric and non-proportional to the growth of stomach weight; stomach volume grows more quickly with an exponent of 1.18 (Fig. 3). Assuming that equations concerning the volume and surface area of a sphere 
hold true for perch stomachs and approximating stomach weight as surface area $\times$ stomach wall thickness, the exponent of the stomach weight-stomach volume relationship would be 1.5 if the thickness of the stomach wall remained constant while the radius of the stomach increased. On the other hand, if the wall thickness increased proportionally to the radius, the exponent would be 1 . The value of 1.18 matches the model in which wall thickness is a function of the radius raised to the power of about 0.54 ; when the radius of the stomach doubles and the volume increases eightfold, the wall thickness increases by about $45 \%$.

The dynamics of stomach size to fish size observed in this study match the gradual ontogenic shift commonly observed in perch: from zooplankton feeder gradually to benthic invertebrate feeder and finally to piscivorous predator when they reach the length of about $15 \mathrm{~cm}$ (e.g. McCormack 1970). This is, among other things, a successful strategy for reducing competition for food. During this process, the size of prey in relation to fish size first increases when the growing fish switches from plankton to benthic invertebrates, and this can happen again when switching to fish food. However, it has been reported that even $0+$ perch can employ different feeding strategies and become piscivorous at lengths of only a few centimetres (Borcherding 2006). Young and rather small individuals are most abundant in lake fish communities, and after becoming able to swallow and digest these animals, predators do not gain much of an advantage by increasing their stomach weight and volume with growth in length. In that respect, a decrease in stomach growth or a proportional decrease in size is understandable and even profitable. Our results thus support Ruohonen and Grove's (1996) suggestion that it is uneconomical to maintain extra stomach capacity. Admittedly, it is simplistic to consider only the size of the largest food items that can be contained in the stomach. Further analyses of the optimal stomach size during ontogeny should thus consider the availability of different-sized food items in relation to optimal foraging, gape-limitation and maximum food size (e.g. Schael et al. 1991) and the gastric evacuation rate in relation to meal size (e.g. Pääkkönen et al. 1999).

Depending on food availability and feeding habits, there may be differences in the fish size-stomach size relationship between aquatic ecosystems. Although the scatterplots based on the two lakes in our study overlap nicely, controlled experiments should be conducted, and more data from different types of lakes should be obtained to reveal the roles of environmental and genetic component factors in the fish size-stomach size relationship.

Acknowledgements We thank Antti Granqvist for his valuable contributions to data collection and analysis.

Funding Information Open access funding provided by University of Jyväskylä (JYU).

\section{Compliance with ethical standards}

Conflict of interest The authors declare that they have no conflict of interest.

Ethical approval The authors followed all applicable international, national and institutional guidelines for the care and use of animals.

Open Access This article is distributed under the terms of the Creative Commons Attribution 4.0 International License (http://creativecommons.org/licenses/by/4.0/), which permits unrestricted use, distribution, and reproduction in any medium, provided you give appropriate credit to the original author(s) and the source, provide a link to the Creative Commons license, and indicate if changes were made. 


\section{References}

Borcherding J (2006) Prey or predator: 0+ perch (Perca fluviatilis) in the trade-off between food and shelter. Environ Biol Fish 77:87-96

Cant JP, McBride BW, Croom WJ Jr (1996) The regulation of intestinal metabolism and its impact on whole animal energetics. J Anim Sci 74:2541-2553

Craig JF (1978) A study of the food and feeding of perch, Perca fluviatilis L., in Windermere. Freshw Biol 8:5968

Elliot JM, Persson L (1978) The estimation of daily rates of food consumption for fish. J Anim Ecol 47:977-991

Froese R (2006) Cube law, condition factor and weight-length relationships: history, meta-analysis and recommendation. J Appl Ichthyol 22:241-253

German DP, Neuberger DT, Callahan MN, Lizardo NR, Evans DH (2010) Feast to famine: the effects of food quality and quantity on the gut structure and function of a detritivorous catfish (Teleostei: Loricariidae). Comp Biochem Phys A 155:281-293

Jacobsen L, Berg S, Baktoft H, Skov C (2015) Behavioural strategy of large perch Perca fluviatilis varies between a mesotrophic and a hypereutrophic lake. J Fish Biol 86:1016-1029

Jobling M (1980) Gastric evacuation in plaice, Pleuronectes platessa L.: effects of temperature and fish size. J Fish Biol 17:547-551

Jobling M, Gwyther D, Grove DJ (1977) Some effects of temperature, meal size and body weight on gastric evacuation time in the dab Limanda limanda (L.). J Fish Biol 10:291-298

Känkänen M, Pirhonen J (2009) The effect of intermittent feeding on feed intake and compensatory growth of whitefish Coregonus lavaretus L. Aquaculture 288:92-97

Kasumyan AO (2000) Individual variability of taste preferences and of behavioral response to taste stimuli in carp Cyprinus carpio. J Ichthyol 40:661-669

Krogdahl Å, Bakke-McKellep AM (2005) Fasting and refeeding cause rapid changes in intestinal tissue weight and digestive enzyme capacities of Atlantic salmon (Salmo salar L.). Comp Biochem Phys A 141:450-460

Mattila J, Koskela J, Pirhonen J (2009) The effect of the length of repeated feed deprivation between single meals on compensatory growth of pikeperch Sander lucioperca. Aquaculture 296:65-70

McCormack J (1970) Observations on the food of perch (Perca fluviatilis L.) in Windermere. J Anim Ecol 39: 255-267

Mehner T, Wieser W (1994) Energetics and metabolic correlates of starvation in juvenile perch (Perca fluviatilis). J Fish Biol 45:325-333

Mélard C, Kestemont P, Grignard JC (1996) Intensive culture of juvenile and adult Eurasian perch (P. fluviatilis): effect of major biotic and abiotic factors on growth. J Appl Ichthyol 12:175-180

Pääkkönen JPJ, Myyrä R, Marjomäki TJ (1999) The effect of meal size on the rate of gastric evacuation of burbot, Lota lota (L.). Ecol Freshw Fish 8:49-54

Phelps QE, Willis DW, Powell KA, Chipps SR (2007) A method for determining stomach fullness for planktivorous fishes. N Am J Fish Manag 27:932-935

Pirhonen J, Koskela J (2005) Indirect estimation of stomach volume of rainbow trout Oncorhynchus mykiss (Walbaum). Aquac Res 36:851-856

Popova OA, Sytina LA (1977) Food and feeding relations of Eurasion perch (Perca fluviatilis) and pikeperch (Stizostedion lucioperca) in various waters of the USSR. J Fish Res Board Can 34:1559-1570

Ruohonen K, Grove DJ (1996) Gastrointestinal responses of rainbow trout to dry pellet and low-fat herring diets. J Fish Biol 49:501-513

Schael DM, Rudstam LG, Post JR (1991) Gape limitation and prey selection in larval yellow perch (Perca flavescens), freshwater drum (Aplodinotus grunniens), and black crappie (Pomoxis nigromaculatus). Can J Fish Aquat Sci 48:1919-1925

Schleuter D, Eckmann R (2008) Generalist versus specialist: the performance of perch and ruffe in a lake of low productivity. Ecol Freshw Fish 17:86-99

Publisher's note Springer Nature remains neutral with regard to jurisdictional claims in published maps and institutional affiliations. 